\title{
Nanotechnology Commercialization: Prospects in India
}

\section{Mazumder $\mathrm{S}^{*}$, Sarkar $\mathrm{D}^{1}$ and Puri $\mathrm{IK}^{2}$}

${ }^{1}$ Department of Chemical Engineering, Birla Institute of Technology and Science, Pilani, Rajasthan, India ${ }^{2}$ Department of Mechanical Engineering, Department of Engineering Physics, and Department of Materials Science and Engineering, McMaster University, Hamilton, Canada

*Corresponding author: Mazumder S, Department of Chemical Engineering, BITS Pilani, Rajasthan, Fax: +91 1596-244183, Tel: +91 1596-515725, E-mail: sonal.mazumder@gmail.com

Citation: Mazumder S, Sarkar D, Puri IK (2014) Nanotechnology Commercialization: Prospects in India. J Mater Sci Nanotechnol 2(2): 201. doi: 10.15744/2348-9812.1.402

Received Date: November 14, 2014 Accepted Date: December 03, 2014 Published Date: December 10, 2014

\begin{abstract}
Nanotechnology manipulates and creates matter to formulate nanometer scale materials and objects. It is an interdisciplinary field that involves a wide range of scientific and engineering disciplines, and has societal implications. The past few decades have produced nanotechnology innovations and applications for agriculture, healthcare and medicine, biotechnology, energy and environment, materials science, electronics, information technology, telecommunication and manufacturing. Governments and private investors, including venture capitalists, have made considerable investments in emerging nanotechnologies. Both large organizations and new startup companies are exploring options to commercialize nanotechnology-based products. This review examines the commercialization of nanotechnology by considering the strategies of large corporations and start-up firms, and the major challenges facing the adoption and diffusion of nanotechnology. Its primary focus is the development of nanotechnology research and industry in India, which, as a test case, helps identify the challenges and strategies for nanotechnology commercialization in emerging economies. Much of nanotechnology R\&D in India remains conceptual. Fundamental research is not robustly linked to viable commercial production and large-scale manufacturing, but this could be improved by enhancing IP protection, regulations and ethical guidelines. Enhancing nanotechnology R\&D, and commerce, will require a policy focus on infrastructure, education, standards and workforce preparation.
\end{abstract}

\section{Introduction}

Nanotechnology uses the principles of science and engineering to design and manufacture products from atoms, molecules and nanoparticles. According to the US National Nanotechnology Institute (NNI), nanotechnology is defined as "Research and technology development at the atomic, molecular and macromolecular levels, in the length scale of approximately 1-100 nanometer range, to provide a fundamental understanding of phenomena and materials at the nanoscale and to create and use structures, devices and systems that have novel properties and functions because of their small and/or intermediate size. Nanotechnology research and development includes manipulation under control of the nanoscale structures and their integration into larger material components, systems and architectures."[1]. In June 2014 the FDA released guidelines that expanded the existing definition to include materials in the usual nanoscale range (approximately $1 \mathrm{~nm}$ to $100 \mathrm{~nm}$ ), as well as any larger products up to $1000 \mathrm{~nm}$ that are engineered to have properties that are caused by their dimensions. By "engineered", they referred to products that have certain dimensions or exhibit certain properties by virtue of deliberate and purposeful manipulation. According to FDA, "Nanotechnology is an emerging technology that can be used in a broad array of FDA-regulated products, including medical products (e.g. to increase bioavailability of a drug), foods (e.g., to improve food packaging) and cosmetics (e.g. to affect the look and feel of cosmetics). Materials in the nanoscale range (i.e., with at least one dimension in the size range of approximately 1 nanometer $(\mathrm{nm})$ to 100 ( $\mathrm{nm}$ ) can exhibit different chemical or physical properties, or biological effects compared to larger-scale counterparts. For example, dimension-dependent properties or phenomena may be used for functional effects such as increased bioavailability, decreased dosage, or increased potency of a drug product, decreased toxicity of a drug product, better detection of pathogens, more protective food packaging materials, or improved delivery of a functional ingredient or a nutrient in food. These effects may derive from altered chemical, biological, or magnetic properties, altered electrical or optical activity, increased structural integrity, or other unique characteristics of materials in the nanoscale range not normally observed or expected in larger-scale materials with the same chemical composition. Materials or end products may also exhibit similar properties or phenomena attributable to a dimension(s) outside the nanoscale range of approximately $1 \mathrm{~nm}$ to $100 \mathrm{~nm}$."

Since Richard Feynman's well known statement made in 1959, “There is a plenty of room at the bottom," nanotechnology has transformed how products are fabricated. Like other disruptive technologies, it is catalyzing economic growth [2-4]. Early nanotechnology milestones included the first molecular device in 1974 [5] and the scanning tunnelling microscope in 1981 [6], the understanding of the carbon nanotube [7], and the DNA nanomechanical device [8]. 
While some nanotechnology innovations have been revolutionary, others were incremental. Several nanotechnology applications have evolved through the confluence of novel materials with new device architectures [1]. Commercial products include sunscreen composed of titanium dioxide nanoparticles [9], nanodevices for drug delivery and surgical tools [10], early disease diagnosis [11],nanocoatings in sunglasses [12], nanocomposites in cars[13], quantum dots for medical imaging [14] and carbon nanotubes for field emissive displays[15].

This R\&D activity has provided commercial opportunities, and prompted governments and corporations to implement rapid commercialization strategies [40]. The U.S. National Science and Technology Council estimates revenue from nanotechnology products and services to be about $\$ 1$ trillion [40]. This includes $\$ 300$ billion for electronics and communication, $\$ 340$ for materials and material processing, $\$ 180$ billion for pharmaceuticals, $\$ 100$ billion for chemical manufacturing, $\$ 70$ billion for aerospace, $\$ 45$ billion for sustainability, $\$ 22$ billion for sensors and instrumentation, and $\$ 30$ billion for improved healthcare.

One appraisal counts more than 2500 companies in over 48 countries that are involved in nanotechnology research, manufacturing or applications [16]. The U.S., with around 1200 companies, is the major hub for nanotechnology firms. Figure 1 shows the distribution of nanotechnology firms in different countries [17]. Over 270 of these companies are involved in the manufacture of raw materials such as nanoparticles, nanofibers and nanowires, carbon nanotubes, and quantum dots. More than 340 companies are active in the life sciences and pharmaceuticals. The vast majority with well over half of all companies manufacture instruments, devices, or advanced materials and components.

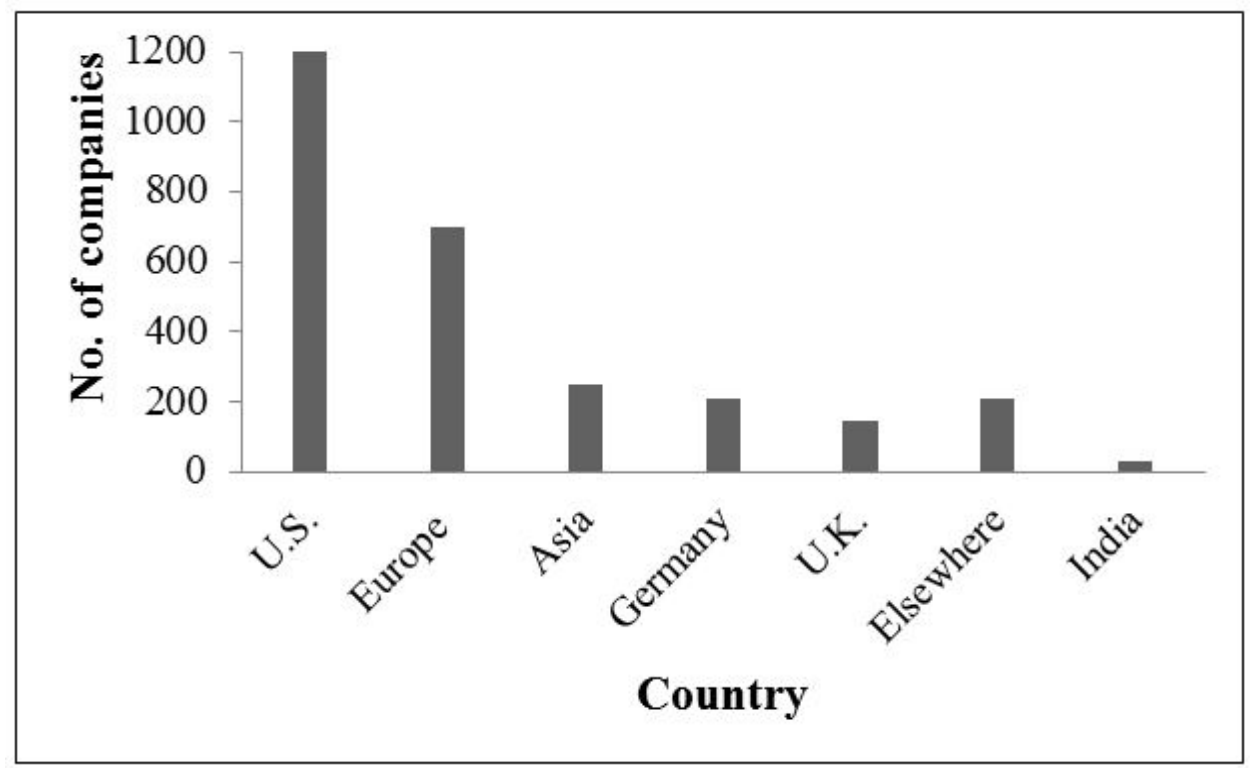

Figure 1: Number of companies involved in nanotechnology in different countries $[16,17]$

\section{Nanotechnology Industry}

The invention of tools to image and manipulate molecular species and nanoparticles, such as the scanning tunnelling microscope (STM) and atomic force microscope (AFM) [18] boosted nanotechnology R\&D. Such tools led to an explosive growth in publications and patents [19,20] due to substantial support from governments, universities and investors [21,22]. The two major pathways for nanotechnology commercialization have been through start-up firms funded mainly by government grants and venture capital (with examples of Carbon Nanotechnologies Inc., Molecular Electronics Inc., InMat Inc. and Zyvex), or through large corporations, e.g., IBM, Hewlett-Packard, Motorola and Texas Instruments1.Most start-ups and spin-off firms were nurtured and formed in a university environment, typically founded by professors, graduate students and research scientists. The success of early stage commercialization depends on the future marketplace and the entrepreneurial expertise of the researchers and entrepreneurs who conceive products. The nanotechnology marketplace is promising and includes, for example, the automotive, aerospace, electronics, energy, food, medical, and pharmaceutical industries. Existing uses of nanotechnology typically focus on performance improvement.

\section{Nanoelectronics}

Nanotechnology advances in the electronics industry have allowed transistors to be scaled down to quantum dimensions, enabling the further miniaturization of logic and memory devices [23]. Quantum mechanical confinement has been used to devise a high electron mobility transistor and a quantum well laser [24]. Such a semiconductor device greatly improves reliability, efficiency, noise reduction and processing speed [18]. Organic molecules have been used to fabricate molecular wires and switches, and unimolecular rectifiers and molecular field effect transistors, which will hasten the development of quantum computers and nanodevices that have extraordinary computational speed [25]. Other applications of nanoelectronics include spintronics, memory and storage devices, hard drives and tapes, optical switching and display technologies $[2,18,26]$. 


\section{Nanobiotechnology}

Applications of nanotechnology in medicine and healthcare include diagnostic tools, methods for the early detection and prevention of diseases, drugs and drug discovery, and prosthetics and implants [27]. Nanodevices, such as non-invasive or minimally invasive surgical tools, gene chips and biochemical sensors have shown potential for the early detection and prevention of diseases [2,26]. Nanotechnology implants can monitor the body chemistry of patients and trigger drug release at a specific location inside the body [28]. Biodegradable and nontoxic nanoparticles have been used in drug and gene delivery, and clinical trials on the resulting nanodrugs are underway [29,30]. Research on nanoengineered artificial limbs and prostheses has shown that these can be fully integrated with the human body. Biological implants and nanoelectronic devices can be used to enhance sight for the vision impaired and hearing for those who are hard of hearing [31].These nanobiotechnology developments provide hope for personalized medicine by developing patient-specific treatments for diseases and disabilities [29]. There are several licensed nanotechnology based products in pharmaceutical. Some of the early examples are NanoCrystal ${ }^{\circledR}$ technology (formerly Élan Corporation, now Alkermes; http://a.alermes.com/rd/technology.aspx) for APIs that have poor water solubility. According to a report by Cientifica 2007, there are many products based on liposome nanotechnology, nanosuspension, polymer therapeutics, vaccines, nanoshell technology, nanocrystal and nanotube from several countries such as US, UK, Australia, Japan and Asia. Several other products such as nanosensors, gold nanoparticles, niosomes, dendrimers, are still in R\&D phases.

\section{Nanomachines}

A nanoelectromechanical (NEMS) system is a smaller microelectromechanical (MEMS) system that integrates electrical and mechanical functionality on the nanoscale. It typically includes a nanomachine that incorporates transistor-like nanoelectronics with mechanisms such as pumps, motors or actuators, to form sensors. The transducer in NEMS converts mechanical energy into electrical energy or an optical signal, or vice versa [32]. Example applications of NEMS include highly sensitive, ultrafast, high resolution actuators and sensors, such as mechanical charge detectors, mechanical devices for high frequency signal processing, biological imaging and quantum measurement, and mechanical filters in radio frequency (RF) devices [33].

\section{Other applications}

Currently, it is not mandatory for a nanomaterial or a product employing nanotechnology to be licensed, although they must be approved depending on their use and must be safe in accordance with the Chemicals Act. Recently, regulations have been made in some countries with respect to using nano-additives in food. For instance, in the EU they need to pass a special approval procedure even if they have been licensed before. Food packaging that contains nanoparticles don't need to be approved, but should not release any nano substances into the food. Thus, a clear delineation must be made between licensed and non-licensed nanotechnology products. Usually, pharmaceutical products that use nanotechnology are licensed, while others aren't.

Common applications include those for sunscreens and cosmetics that use nanoparticles of titanium dioxide (e.g. from Altair Nanotechnologies and Oxonica) and zinc oxide nanoparticles (Advanced Powder Technologies, Micronisers and Nanophase/ BASF) to protect the skin from ultraviolet light [9]. Polymer nanocomposites are used to make clothing materials that are resistant to stain and wrinkling, e.g., those sold as Nano-Care, Nano-dry, Nano-Peel, and Nano-Touch (by Nano-tex). Eddie Bauer uses nano-whiskers to the generate stain repellent product Nano-Pants [34]. Nanogate Technologies GmbH, PPG Industry, AFG industry and Pilkington use nanocomposites and titanium dioxide nanoparticles to make coatings for anti-scratch lenses, selfcleaning glasses and anti-stick coatings [35]. Sports goods such as tennis balls and racquets made from nanocomposites of Nano clay, and synthetic polymers and carbon nanotubes have superior performance attributes than their conventional counterparts [40]. Nanoplex technologies Inc. uses metals to create nanobar codes that find use for biocatalysts in protein arrays [36]. The print quality, throughput and image resolution of ink products is enhanced with Nano particulate pigment colorants (Hewlett-Packard) [37]. Nanomaterial is embedded in MEMS devices that are used as smart sensors in automotive applications (e.g., manufactured by Analog Devices and MEMCAP [38]). Toyota uses plastic nanocomposite material for the timing belt and underhood parts in the Toyota Camry model because of their overall mechanical robustness [39]. General Motors also uses a polymer nanocomposite for "step assists" in its Safari and Astro vans since it is lightweight, scratch resistant and rust proof [40]. Exxon Mobil uses specialty zeolite catalysts for petroleum processing [40]. Companies such as Samsung, Ntera, NanoChromics, and E-Ink produce commercial products containing nanomaterial's, ranging from TVs and computer monitors toe-paper [40].Other applications include automobile and spacecraft lubricants, nanofiltration products, packaging bottles, sports equipment, pregnancy kits and synthetic bones [40].

\section{Funding}

The major sources for nanotechnology R\&D include government agencies, large corporations, venture capital, and universities. The US government has steadily invested in nanotechnology (upward from \$116 million in 1997 to \$774 million in 2003 and increasing to $\$ 2.18$ billion in 2011) [40]. Other nations, e.g., Japan, the countries of the EU, China, Australia, Taiwan and Israel, have also invested substantially in nanotechnology [41]. The total global investment was \$67.5 billion in 2011 [1]. Worldwide spending on nanotechnology R\&D is projected to be around $\$ 100$ billion by the end of 2014 [22]. These investments are depicted through Figure 2. 


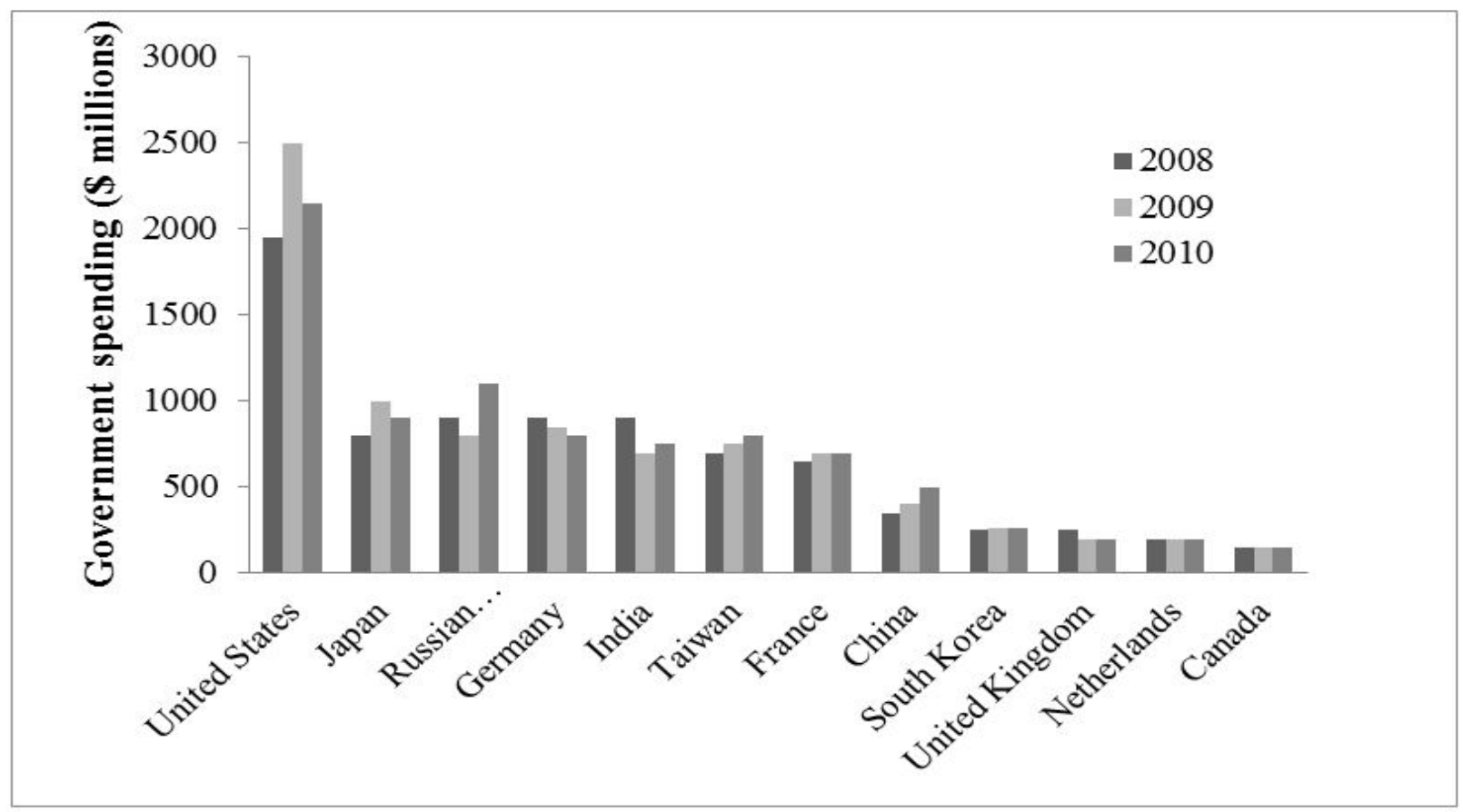

Figure 2: Government investment in nanotechnology [42].

Large companies are directly or indirectly involved in nanotechnology R \& D investment. Some major companies in the U.S. include Hewlett Packard, IBM, Intel, Motorola, Texas Instrument, Dow Chemical and Raytheon [40]. Their Japanese counterparts are NEC Corporation, Toshiba, Nihon Shinku, Gijustu, NTT Docomo, Fujitsu and Sony [40]. Venture capitalists have spent almost $\$ 900$ on nanotechnology start-up firms since 1999 [41]. Universities have also funded nanotechnology research and development and start-up firms [40].

\section{Nanotechnology Commercialization}

Technology commercialization combines technical, commercial and financial techniques to transform a new technology into products and services that can be used by the consumer [43]. This process includes a range of activities, such as collating ideas for technology commercialization, incubating them, developing the technology in question, constructing a prototype, modifying the process to fit market demands and/or production abilities, optimizing the process, marketing the technology, and creating new infrastructure [44].

Consumers became more fully cognizant of nanotechnology in the early 2000s when commercial products began to include tags referring to nanotechnology. The early adoption was of passive nanomaterials. During a 'silver wave', silver nanoparticles were seen in food packaging, clothing, disinfectants and other household appliances [45a]. Carbon nanotubes were introduced in stainresistant textiles and cerium oxide in fuel as a catalyst [45b]. A 2011 estimate identified over 1300 nanotechnology products being marketed, with new ones introduced at a pace of 3-4 per week [46].

\section{Commercialization Phases}

The commercialization process goes through various steps [47] as follows.

Inception: The first step during commercialization is protecting the intellectual property (IP) of the firm which is typically done by filing a patent, trademark, copyright or trade secret. This is mainly done to prevent theft, protect against independent discovery and safeguard business interests in order to maintain a market share. Many start-ups obtain their initial IP from universities or government labs whereas established firms tend to spin out a business unit created specifically for this purpose [48]. Although not the norm, sometimes nanotechnology start-ups are formed by an independent entrepreneur who generates the IP autonomously [48]. Apart from a strong IP position, a firm must have a simple, clear and compelling business plan. In addition to patents, trademarks and copyrights, protection of materials also involves trade secrets, that is manufacturing or other processes that remain undisclosed to the public (not in patent filings) which protect the materials because they remain secret such as the formulation of Coca Cola. This is used in other industries, including pharmaceuticals. According to the United States Patent and Trademark, Department of Commerce" Trade secrets consist of information and can include a formula, pattern, compilation, program, device, method, technique or process. To meet the most common definition of a trade secret, it must be used in business, and give an opportunity to obtain an economic advantage over competitors who do not know or use it." 
Funding: Sources of funding typically considered for a nanotechnology firm are venture capitalists, grants and contracts through government (through national and regional agencies),corporate partners, angel funds, collaborations with larger firms and even friends and family [48]. Venture capitalists believe in business models and are better convinced by strategies that seek to tap into a large market opportunity. One report claims that the track record of companies with high-profile academics who have generated a part or the whole of the firm's IP has been more successful than of others [48].

Market positioning: The primary objective of any firm is to build market position for which it can adopt several strategies. For instance, the firm can partner with a larger corporation that provides access to established manufacturing and sales channels, both of which are capital and time intensive to develop for a start-up. Another approach is to adopt know-how from a common underlying technology by placing a strong management team that has sufficient market knowledge [48].

\section{Challenges to Technology Commercialization}

New technologies and inventions often draw attention because of their ingenuity, but a product must also be useful and compelling, enabling it to be assimilated into everyday life. A convincing goal would be to identify a market for what nanotechnology has to offertoday [49].Froma business perspective, the essential elements for the successful commercialization of a specifically directed nanotechnology include market size, market potential, and the current economic scenario [50]. Common challenges faced by nanotechnology firms are:

Time Lag: The average time delay between research completion and commercialization of a nanotechnology can lie between three to ten years [45]. Venture capitalists and other commercial sources of funding find this lag to be a major detriment since their capital is now blocked [51].

Valley of Death: This is the interlude between a researcher obtaining positive scientific results and securing funds for commercialization and proto-typing [51]. Estimates for the United States indicate that for every dollar that is invested into basic research, almost a hundred must be invested in commercializing a competitive product [51]. Often, scientists are not interested in commercialization, which leads to technologies being lost.

Lack of infrastructure: Nanotechnology research is dependent on expensive instruments. Hence, a lack of infrastructure retards nanotechnology growth. Furthermore, equipment becomes quickly out-dated, making it harder for researchers to keep abreast of the competition [51].

Lack of standard for evaluation: A major obstacle for manufacturing nanoproducts is the lack of an organization that develops standards and issues certificates. Because of this, normalizing standards by which nanotechnologies can be evaluated are lacking.

Bureaucratic delays: Patent offices take up to thirty-six months to respond to a single application, a serious problem when even a slight delay can be detrimental. There is a current lack of a coherent policy on technology transfer from universities to start-up businesses due to which a considerable red tape must be dealt with for any such transfer [45].

Dearth of funding: Since it is capital intensive (e.g., the procurement of the latest instruments and updated facilities), nanotechnology research faces challenges in obtaining funding. Commercialization requires large investments which small to medium firms are often unable to secure.

Lack of trained professionals: The lack of sufficiently trained scientists, engineers, technicians, and researchers in the country is another barrier [51]. This is mostly due to lack of addition of nanoscience and technology in the engineering and science syllabus.

Public support: Favourable public disposition towards any emerging technology, nanotechnology included, is beneficial. Corporations with established brands use a 'brand image' to sway public sentiments in their favour but small firms and start-ups that currently constitute a major chunk of nanotechnology product firms do not have that advantage and are thus more vulnerable to misdirected public outcry [47].

\section{Nanotechnology Commercialization in India}

In India, nanotechnology is a publicly driven initiative for which industry participation is at an elementary stage [53]. Therefore, government agencies and R\&D organizations are the key players in the national context. Among government agencies, the Department of Science and Technology (DST) is primarily responsible for organizing, coordinating and promoting science and technology activities. The Nanoscience and Technology Mission (NSTM) and Nanoscience and Technology Initiative (NSTI) established by DST champion nanotechnology [52]. Beside DST, other agencies, including the Council of Scientific and Industrial Research (CSIR), Department of Biotechnology (DBT), agencies under the Ministry of Information and Communication Technology, Ministry of Family Health and Welfare, Ministry of Defense, Ministry of New and Renewable Energy have promoted nanotechnology R\&D [53]. Nanotechnology research is carried out in various academic and scientific institutions. Foremost among these are the Centers of Excellence (Coe) for Nanoscience and Technology that have been established through the NSTM by DST [53].

Companies in India that are engaged in nanotechnology R\&D include Cranes Software International Limited, Monad Nanotech, Velbionanotech, Innovations Unified Technologies, Qtech Nanosystems, and Naga Nanotech India. Leading companies such as Reliance, Tata Group, and Mahindra and Mahindra have also made nanotechnology investments [53]. There are around thirty new companies in India that are commercializing nanotechnology products [53]. 


\section{Nanotechnology Stakeholders in India}

\section{Government Agencies}

The Department of Science and Technology is the organization primarily responsible for organizing, coordinating and promoting science and technology related activities in India. The department established NSTM and NSTI [52]. Several other agencies also support nanotechnology R\&D. The Department of Biotechnology supports nanotechnology research that intersects with the life sciences [54]. Thirty-eight laboratories under the Council of Scientific and Industrial Research (CSIR) conduct nanotechnology R\&D in varied areas [55]. The Department of Information Technology (DIT) under the Ministry of Information and Communication Technology and the Indian Council of Medical Research under the Ministry of Family Health and Welfare support the expansion of nanotechnology in electronics [56] and health [56], respectively. The Ministry of New and Renewable Energy (MNRE) [57] likewise develops photovoltaics and fuel cells [53]. The Defense Research and Development Organization (DRDO) [58] and the Department of Atomic Energy (DAE) also contribute to nanotechnology R\&D [59]. Other agencies include Ministry of Commerce [60] and Ministry of Agriculture [53].

\section{Public Sector R\&D Institutions}

Research is being carried out in private, and academic and scientific institutions. Most visible are the Centers of Excellence (CoE) for Nanoscience and Technology, established under the NSTI by DST [53]. These consist of eleven 'Units of Nanoscience' created to pursue basic research in multiple areas of nanoscience and nanoscale systems and technology. Seven 'Centers for Nanotechnology' have been established to pursue R\&D in specific domains, e.g., nanoelectronics at IIT Bombay and nanoscale phenomena in biological systems and materials at Tata Institute of Fundamental Research (TIFR). There is a 'Center for Computational Material Science' at Jawaharlal Nehru Centre for Advanced Scientific Research (JNCASR) [55]. The S.N. Bose National Centre for Basic Sciences (SN Bose NCBS), Association for the Cultivation of Science (IACS), the Indian Institute of Science (IISc), JNCASR and IIT Kanpur, each host a Unit of Nanoscience as well as a Centre for Nanotechnology. These CoEs and others at IIT Mumbai, Chennai and Delhi are considered to be leading institutes for nanoscience and nanotechnology research. Autonomous institutes like the IITs, IACS, SN Bose NCBS and Saha Institute of Nuclear Physics (SINP) have the largest representation in the CoEs, followed by deemed universities like IISc and JNCASR [53]. Jadavpur University leads in postgraduate and doctoral programmes in nanoscience and technology. While the bulk of R\&D has been undertaken at autonomous institutes, only $3 \%$ of the total R\&D activity is performed in universities [61].

The improvement in the quality of nanotechnology R\&D in India is estimated to require a critical mass of 150 working groups [53]. Thus, a major policy aim is to develop a conglomeration of ' $50-60$ science and technology units, including IITs and NITs to facilitate the creation of nano-clusters across the country' To expand the R\&D base, DST has provided support and financial assistance to various institutions that house nanotechnology centres. Since the CoEs and other centres are spread throughout India, this has produced a decentralised approach to nanotechnology research. Both Bangalore and Kolkata host 5 CoEs each and a proposed INST, and are hubs for nanoscience and technology. Bangalore's pre-existing information technology and biotechnology sectors could provide a convergence among these emerging technologies, leading to interdisciplinary approaches to nanotechnology R\&D. Tamil Nadu, Karnataka and Kerala contain numerous engineering institutions, which could augment the development of applications and devices [53].

\section{Industry}

A handful of companies in India engage in nanotechnology R\&D. Cranes Software International Limited focuses on MEMS and nanotechnology R\&D by supporting institutions such as IISc Bangalore [62]. Velbionanotech was ranked in ASIA's Top 100 Bio Nanotechnology companies by Red Herring in 2005 [63]. Its core expertise is designing drugs to ameliorate cardiac disease, kidney stones, AIDS and cancer, and producing generic cosmetic products. Monad Nanotech produces carbonaceous nanomaterials (CNM) using low cost production techniques developed at IIT Mumbai [64]. The company has sales rights in India and Canada for Shenzhen Nanotech Port Co. Ltd., China, and marketing rights for the products of Meijo Nano Carbon, Japan. Unified Technologies was conceptualized by a group of IIT Bombay alumni that produces carbon nanotubes in a pilot plant [53]. Qtech Nanosystems incubates products based on nanotechnology, such as nanopositioning stages and other precision applications [65].

\section{Non-Governmental Organisations}

Nongovernmental organisations constitute a middle ground between academia and the industry. The Nanotechnology Research and Innovation Foundation (India Nano) [66] is such an organisation supported by experts with academic and industrial backgrounds that promotes strategic collaborations to advance technology. It has an Innovation Acceleration Network (IAN) programme that is designed to bridge the gap between invention and commercial reality, by providing support for entrepreneurs. The Nanotechnology Research and Innovation Foundation and the Regional Research Laboratory, Trivandrum (RRL-T) have forged a strategic partnership that pools their respective expertise and facilitates commercialization of technologies [65]. The Nano Science and Technology Consortium encourages growth, promotion and partnering in nanoscience and technology [67]. It brings together industries, academics and government through consultative, advisory and educative processes to facilitate the growth of nanotechnology. 


\section{India-Specific Challenges}

Nanotechnology has the potential to address key challenges related to energy, agriculture, water, health and the environment. Herein, we give examples of two of these challenges, namely for energy and water, by examining the current scenario and development hindrances, and then suggesting next steps.

\section{Energy}

India ranks fifth in the world in total energy consumption but more than $25 \%$ of its primary energy requirements are met through import [53]. The high growth rate of Indian industries has accelerated the need and development of energy resources. Although India's hydrocarbon resources are negligible $(0.4 \%$ of the world's total reserves), it has abundant renewable energy sources, such solar, wind, hydroelectric power and bioenergy [53,68].

Nanotechnology can contribute through developments related to renewable energy, e.g., photovoltaic cells, organic light-emitting devices based on quantum dots, and carbon nanotubes in composite film coatings for solar cells [53]. Nano catalysts for hydrogen generation and novel hydrogen storage systems based on lightweight materials like carbon nanotubes offer promising developments [69]. A major global R\&D focus is in solar photo voltaics (SPV) for which USA, Europe, Japan and China are currently research frontrunners [70,71]. Increasing the efficiency of single junction photovoltaic (PV) solar cells based on inorganic semiconductor nano crystals (NCs) (such as spherical quantum dots (QDs), quantum rods (QRs), or quantum wires (QWs) can help improve efficiency from $33.7 \%$ to $44.4 \%$ [53].

Nanotechnology-based interventions in solar energy systems are being pursued in India [65]. The local aim is to improve the overall SPV process efficiency, reduce the cost of solar cells and search for alternate semiconductors due to a shortage of silicon. SPV research in India is primarily aimed at developing new materials, processes, device structures and modules using multi crystalline silicon, thin films, polymers, nanoparticles, nano rods and quantum dots [53]. Research institutes are engaged in different areas of SPV research with support from MNRE and DST. Research in energy storage devices and efficient lighting systems is also being undertaken. Various government and private companies, e.g., CEL, BEL, BHEL, Moserbaer Photovoltaic, Tata-BP Solar, Maharishi Solar Technology, and Signet Solar India, investigate advanced multi-crystal and thin film solar cells and panels using indigenous and imported technologies. However, since industry-university interactions in India are not as strong as in other countries, product development and characterisation is often ignored so that notable innovations never make it out of a laboratory [53].

\section{Water}

Water poses a serious challenge for India in its available quantity and quality. Population expansion, rapid urbanisation, industrialisation and agriculture are the major reasons that exacerbate this problem. The annual per capita availability of freshwater during the first fifty years of independence (1947-1997) fell from $6000 \mathrm{~m}^{3}$ to $2300 \mathrm{~m}^{3}$. The country is predicted to face an acute water shortage by 2050 [53,72]. Uneven distribution and over-exploitation of groundwater has lead to decreased availability, while factors like microbial contamination, heavy metals, high salinity and micro pollutants have degraded water quality. Altogether, the cost of environmental damage is estimated to be $\$ 9.7$ billion per year, of which the health impacts of water pollution account for $59 \%$ of the total value of degradation [53,72].

Possible interventions include the use of nano membranes (for water purification, desalination, and detoxification), nanosensors (for detection of contaminants and pathogens), nanoporous zeolites, nanoporous polymers, attapulgite clays for water purification, magnetic nanoparticles (for water treatment and remediation), and $\mathrm{TiO}_{2}$ nanoparticles (for the catalytic degradation of water pollutants) [73]. Although technologies such as the candle filter, bios and filter, activated carbon, and UV and chemical based systems for removing contaminants from water exist, their performance can be improved and the systems made more efficient using nanotechnology.

Wastewater sewage treatment facilities must be expanded and nanotechnology has a role to play in improving tertiary treatment. Companies such as Madras Fertilizers Limited (MFL), GMR Power Corporation, and Hindustan Petroleum Corporation Limited (HPCL) have set up facilities to reclaim and reuse city sewage water after tertiary treatment. In case of HPCL, the annual operating cost is one-sixth of the cost of municipal freshwater supplied to industries in Mumbai [53]. Further use of technologies such as adsorption, nanofiltration and CNT filters can improve the quality of treated water [74].

Several advances have been indigenously made in water treatment, which are India-specific and affordable as compared to imported technologies. Nanosilver products have been introduced for point-of-use water treatment systems, and incorporated in traditional candle filters for disinfection [75]. After nanosilver-coated candles were tested, the technology was transferred to SBP AquatechPvt. Ltd.to mass-produce and market the candle filters [53].

Nanosilver based carbon blocks have been employed to remove pesticides from. A nanosilver activated carbon block developed in collaboration with IIT, Madras is being marketed by Eureka Forbes as a part in its new water purifier, Aqua guard Total Gold Nova. The treatment includes UV disinfection, along with adsorption on nanosilver based activated carbon blocks. This water purifier was launched in early 2008 and costs USD 154-171 [53]. IICT, Hyderabad has developed a nanosilver coated alumina catalyst using electrochemical methods. These catalysts were found to be efficient for microorganism control in water [53]. Carbon nanotube filters have been prepared and tested successfully for bacteria removal through joint research by Banaras Hindu University and 
Rensselaer Polytechnic Institute [53]. CNT based water filters have also been developed and tested on the laboratory scale by Bhabha Atomic Research Centre (BARC) [53]. Through work at IIT, Kharagpur, iron oxide nanoparticles were chemically synthesized with an average size of $45 \mathrm{~nm}$. Under experimental conditions, a maximum adsorption of 96\% was obtained [53]. While some research on nanomaterial-aided filters and pollutant removal is still at the laboratory stage, two complete systems incorporating nanomaterials (ARCI's nanosilver coated candles and Eureka Forbes activated carbon blocks with nanosilver) have been developed [53]. The ARCI based filters were field tested in forty villages around Hyderabad.

Nanotechnology R\&D in India is still at a formative stage as compared to other nations. Substantial effort is required so that research organisations and industry can successfully engage with nanotechnologies. The majority of nanotechnology R\&D funding is being provided by government agencies. Although the private sector is exploring opportunities in nanotechnology, its expenditures are not yet substantial. Many government agencies, although not at present engaged with nanotechnology R\&D, could enhance capacity. These include ICAR, Ministry of Commerce, Ministry of Water Resources, and Ministry of Food Processing Industries. The Ministry of Environment and Forests could play a key role in filling the gap in risk analyses by encouraging toxicity related studies. Although India (through NSTI) has initiated research collaborations with other countries, it lags behind some countries such as China in terms of nanotechnology investment. Additional investments are required to engage in leading research, build a state of the art infrastructure, and to develop meaningful applications [76].

DST has funded research in areas of semiconductor nanomaterials, carbon nanotubes, nanomaterials for electronic, magnetic and sensor applications, and bio-nanomaterials. DAE has supported semiconductor nanomaterials, DRDO the synthesis of carbon nanotubes, DIT nanomaterials with electronic applications, and DBT the development of bio-nanomaterials. Health has been supported by DST, DBT, ICMR, CSIR and DRDO. MNRE has supported the development of nanomaterials for photovoltaics, hydrogen energy and fuel cells. DST and DBT have interests in developing water filters incorporating nanomaterials. DBT supports plant and animal biotechnology, bio pesticides, genetics, and protein engineering. Therefore, with these disparate foci, it is important to have greater coordination among these agencies in their support of nanotechnology R\&D. In India, there is scant research with respect to risks associated with nanotechnology although nanotechnology applications might conceivably pose risks to the public. A few toxicological studies have been supported by various agencies [77-79]. Therefore, larger initiatives are to be made on this front.

There is also lack of regulatory framework that brings the stakeholders together in developing the technology. No concerns' regarding risk is shown in India. Lately some initiatives have been taken for addressing risk issues by Nano Mission and key scientific agencies. National Institute of Pharmaceutical Education and Research (NIPER) is developing regulatory approval guidelines for nanotechnology based drugs and standards for toxicological tests in nano-based drug delivery systems. In 2010, DST appointed a task force which has been asked to advice Nano Mission Council to develop a regulatory body for nanotechnology in India. However, there is only few academic debate but not much progress in establishing regulation. Firms involved in nanotechnology based product development primarily products addressing water, textile, drug delivery have undertaken Life Cycle Analysis (LCA) partnering with research institutes/universities. Standardization remains an area of concern. India, has only taken initial first steps in addressing standardization issue. There is lack of private sector involvement human resource base is restricted to selected institutes and limited number of research groups.

\section{Ethics of Commercialization of Nanotechnology}

Public discussions of technologies such as nuclear energy, agricultural biotechnology and embryonic stem cells illustrate that some nanotechnologies could also raise significant social and ethical concerns [80]. It is important to understand that such issues become matters of concern not because of the underlying science or engineering but because of the specific applications of technologies [81]. For instance, while the scientific basis might be similar, the medical uses of biotechnology generally raise concerns different from those that arise from agricultural applications [82]. Since the term "nanotechnologies" encompasses a wider range of basic science, methods and engineering approaches than does biotechnology, predicting these diverse efforts, other than for near market applications, is difficult [49]. As elucidated by the President of the Council of Advisors on Science and Technology to the US President Barrack Obama, "In the absence of sound science on the safe use of nanomaterials and of technologies and products containing them, the chance of unintentionally harming people and the environment increases. At the same time, uncertainty and speculation about potential risks threaten to undermine consumer and business confidence."

Anticipating those applications that are likely to raise significant social or ethical issues is even more challenging. Some currently envisioned applications of nanotechnologies which are seen as technically feasible may never be realized, while unanticipated future breakthroughs may lead to the rapid development of applications that are currently unforeseen. Fortunately, most social and ethical issues arising from their applications will most likely not be new or unique to nanotechnologies [83]. The newness of a technology does not itself offer evidence against its potential uses [84]. In many cases, the underlying legal and ethical issues raised by new technologies are generally similar to those our society has already faced.

For instance, the United States of America has adopted existing laws and regulations that govern the protection of human health and environment for nanotechnology. The approach in place today is a risk-based one that examines those characteristics and properties of a material that are relevant to considerations about human and environmental safety-such as exposure, bio distribution (including absorption, distribution, metabolism, and excretion), persistence, bioaccumulation, toxicity, and pharmacokinetics- 
and therefore present issues of potential regulatory relevance. This reflects awareness that regulation should be based on the best available science and must evolve as the main body of knowledge and evidence grows.

Nanotechnologies are predicted to provide improvements, such as inexpensive sustainable energy, environmental remediation, radical advances in medical diagnosis and treatment, and more powerful IT capabilities [84,85]. Since these possibilities for the global society and international economy have profound implications, the important question to ask is who will benefit and, more crucially, who might lose out [80]. For instance, the appropriate ownership of intellectual property is advantageous, but experience in genetics shows that patents that are too broad or do not strictly meet the criteria of novelty can be seen to work against the public good [80].

While it is true that nanotechnology has the potential to revolutionize electronics, aerospace, food, healthcare, environment, energy, water and medicine, as with other technologies, its misuse has the potential to harm humanity. Nanotechnology can be used to make weapons with enhanced properties, such as improved body armour and enhanced battlefield communication systems [40], which can be misused. Regulated and beneficial drugs could augment healthcare in rich nations but become unavailable to the poor. Unregulated nanoengineered recreational drugs could be produced and distributed with criminal intent. Nanotechnology promises smaller, cheaper, and more ubiquitous sensing devices [54] that could be linked over networks to provide greater safety, security, and better healthcare. However, these networks could also be used to limit individual or group privacy through covert surveillance, to collect and distribute personal information without consent, and to concentrate access to such information to enable discriminatory policing, profiling, and social sorting [80].

\section{Conclusion}

Nanotechnology is an enabling technology that will impact applications, such as for electronics and computing, materials and manufacturing, health, medicine, energy, and transportation. This review describes some advances in nanotechnology and their economic and consumer benefits. While there is considerable nanotechnology R\&D in India, progress is not as robust as in other nations. Much of nanotechnology R\&D remains at a conceptual level, and fundamental research has not been robustly linked to viable commercial production and large-scale manufacturing. Risk and safety studies are also required to ensure public acceptance. There should be a policy focus on infrastructure, education, standards and workforce preparation. Nanotechnology commercialization in India can be improved by enhancing IP protection, which should attract investors and facilitate commercialization. Government agencies should coordinate their efforts. According to Prof. C.N.R Rao, "The need to consolidate and translate research to products is to be prioritized (Nanomission, India)". More work is needed on identifying ethical issues, studying public perception and regulatory issues. Integrating nanoscience and nanotechnology into the engineering and science curriculum will enable the preparation of the future generation of scientists and engineers.

\section{Acknowledgement}

The authors gratefully acknowledge Dr. Rajib Dey, Reader, Department of Metallurgical and Material Engineering and Dr. Mahua Ghosh Chaudhuri, Lecturer, School of Materials Science and Nanotechnology, Jadavpur University, India for sharing their thoughts, experiences and insights expressed in this paper.

\section{References}

1. Sargen JF (2013) USET: The national nanotechnology initiative (operating report).

2. Ratner M, Ratrner D (2002) Nanotechnology: A general introduction to next big idea. New Jersey, Prentice Hall.

3. Roco MC(1999) Towards a US national nanotechnology initiative. J Nanoparticle Res 1: 435-8.

4. Whitesides G, Love C (2001) Implication of nanoscience for knowledge and understanding. Dordrecht, Netherland, Kluwer Academic Publishers.

5. Aviram A, Ratner M (1974) Molecular rectifiers. Chem Phys Lett 29: 277-83.

6. Binnig G, Rohrer H (1986) Scanning tunnelling microscopy. IBM J Res Devel 30: 355.

7. Iijima S (1991) Helical microtubules of graphitic carbon. Nature 354: 56-8.

8. Mao C, Sun W, Shen Z, Seeman NC (1999) A nanomechanical device based on the B-Z transition of DNA. Nature 397: 144-6.

9. Smijin TG, Pavel S (2011) Titanium dioxide and zinc oxide nanoparticles in sunscreens: focus on their safety and effectiveness. Nanotech, Sci Appl 4: 95-112.

10. Paradise J, Diliberto GM, Tisdale AW, Kokkoli E (2008) Exploring emerging nanobiotechnology drugs and medical devices. Food Drug Law J. 63: 407-20.

11. Choi Y, Kwak J, Park J (2010) Nanotechnology for Early Cancer Detection. Sensors 10: 428-55.

12. Tekaya A, Benameur T, Labdi S, Aubert P (2013) Effect of Ti/TiN multilayer protectivenanocoatings on Zr-based metallic glasses mechanical performance. Thin Solid Films 539: 215-21

13. Chu C (2010) Development of polymer nanocomposites for automotive applications. M.S. Thesis.

14. Bentolila LA, Michalet X, Pinaud FF, Tsay JM, Doose S, et al. (2005) Quantum dots for molecular imaging and cancer medicine. Discov Med. 5: 213-8.

15. Wang QH, Setlur AA, Lauerhaas JM, Dai JY, Seelig EW, et al. (1998) A nanotube based field emission flat panel display. Appl Phys Lett 72: 2912.

16. Berger M (2010) Well over 2000 companies worldwide already involved in nanotechnology.

17. Wolfe J, Hebert P (2003) The Nanotech report 2003. New York, Lux Capital.

18. Wilson M, Kannangara K, Smith G, Simmons M, Raguse B (2002) Nanotechnology: Basic science and emerging technologies.University of South Wales, Australia 29-54. 
19. Ramón C, Angela H (2002) Forecasting the development of nanotechnology with the help of science and technology indicators. Nanotechnology 13: 243.

20. Dora M, Michael (2003) Nanotechnology strength indicators: International rankings based on US patents. Nanotechnology 14: R1.

21. Fishbine G (2002) The investor's guide to nanotechnology \& micromachines.Newyork, John Wiley \& Sons, Inc.

22. Paull R, Wolfe J, Hébert P, Sinkula M (2003) Investing in nanotechnology. Nat Biotechnol 21: 1144-7.

23. Tour JM (2003) Molecular electronics: Commercial insights, chemistry, devices, architecture and programming. Singapore, World Scientific.

24. Henry CH (1993) The origin of quantum wells and the quantum well laser. Quantum well lasers. New Jersey, Academic Press: 1-13.

25. Takeuchi S (2003) Nanodevices for quantum computing using photons. Chemical Physics 70: 183.

26. Uldrich J, Newberry D (2003) The next big thing is really small: How nanotechnology will change the future of your business. Newyork, Crown Business.

27. Sahoo SK, Parveen S, Panda JJ (2007) The present and future of nanotechnology inhuman health care. Nanomedicine 3: 20-31.

28. Jong WHD, Borm PJA (2008) Drug delivery and nanoparticles: Applications and hazards. Int J Nanomedicine 3: 133-49

29. Sakamoto JH, van de Ven A, Godin B, et al. (2010) Enabling individualized therapy through nanotechnology. Pharmacol Res.62: 57-89.

30. The European Cancer Organization (2012) First trial in humans of 'minicells': a completely new way of delivering anti-cancer drugs.

31. Perkowitz S, Press JH (2004) Digital people: From bionic humans to androids. Washington D.C., Joseph Henry Press.

32. Ekinc KL (2005) Electro mechanical transducers at the nanoscale: Actuation andsensing of motion in nano electromechanical systems (NEMS). Small 1: 78697.

33. Huang XMH, Zorman CA, Mehregany M, Roukes ML (2003) Nanoelectromechanical systems: Nanodevice motion at microwave frequencies. Nature $421: 496$. 34. Pathak R (2007) Introduction to biotechnology. Delhi, Atlantic publishers: 218.

35. Mathiazhagan A, Joseph R (2011) Nanotechnology-a new prospective in organic coating -Review. International J Chem Eng Appl 2: 225-37.

36. Keating CD, Natan MJ (2003) Striped metal nanowires as building blocks and optical tags. Advanced Materials 15: 451-4.

37. Wickramanayake P, Parazak DP (1998) Consists of aqueous pigment dispersion anda microemulsion of water insoluble organic compound, hydrotropic amphiphile and water; used in print jet printing. Patent US 5713989.

38. Gogotsi Y, Presser V (2013) Carbon nanomaterials. $2^{\text {nd }}$ Edition New York, CR Press -Taylor and Francis: 200.

39. Auto E (2002) Auto applications of drive commercialization of nanocomposites. Plastic Additives \& Compounding 4: 30-3.

40. Oriakhi C (2004) Commercialization of nanotechnologies. M.S. Thesis, Massachusetts Institute of Technology, Sloan School of Management, Management of Technology Program.

41. Roco MC (2003) Broader societal issues of nanotechnology. J Nanoparticle Res 5: 181-9.

42. Xue A, Hwang D (2011) Nanotechnology funding: Corporations grab the reins. LuxResearch.

43. Butler JS, Gibson D (2011) Global perspectives on technology transfer and commercialization. Massachusetts, Edward Elgar Publishing, Inc.

44. Asian and Pacific Center for Transfer of Technology (2005) Technology transfer principle \& strategy.

45. a) Beer C, Foldbjerg R, Hayashi Y, Sutherland DS, Autrup H (2012) Toxicity of silver nanoparticles - nanoparticle or silver ion? Toxicology Letters. $208: 286-92$.

b) Patra JK, Gouda S (2013) Application of nanotechnology in textile engineering: An overview. J Engineering Techn Res 5: 104-11.

46. The project on emerging nanotechnologies (2011).

47. Naseri R, Davoodi R (2011) In commercialization of nanotechnology in developing countries, 3rd International Conference on Information and Financial Engineering IPEDR, Singapore, IACSIT.

48. Waitz A, Bokhari W (2003) Nanotechnology commercialization best practices.

49. Mazzola L (2003) Commercializing nanotechnology. Nature Biotechnology 21: 1137-43.

50. Hobson DW (2009) Commercialization of nanotechnology. Wiley Interdiscip Rev Nanomed Nanobiotechnol 1: 189-202.

51. McNeil RD, Lowe J, Mastroianni T, Cronin J, Ferk D (2007) Barriers to nanotechnology commercialization. U.S. Department Of Commerce Technology Administration.

52. Department of Science and Technology. Nanomission (2007).

53. The Energy and Resources Institute (TERI) (2009) Nanotechnology developments in India - a status report TERI project: Capability, governance, and nanotechnology developments - a focus on India New Delhi: The Energy and Resources Institute. New Delhi.

54. Department of Biotechnology (2009) Annual report 2008-2009.

55. Centre for Scientific and Industrial Research (2007) Annual Report, 2006-2007.

56. Indian Council of Medical Research (2009) List of extramural research fellowships(RA/ SRF) sanctioned from April 2007 to March 2009.

57. Ministry of New and Renewable Energy (2014).

58. The Hindu (2006) DRDO typhoid kit in market by mid-year, 2006.

59. Department of Atomic Energy (2014).

60. Ministry of Commerce and Industry, Department of Commerce, Government of India (2008) Strategy for increasing exports of pharmaceutical products, 2008 Report of the Task Force

61. Forbes N (2004) Higher education, scientific research and industrial competitiveness: Reflections on priorities for India, 2004, Forbes Marshall, Pune,Science, Technology and Society, Stanford University, Higher education, 2004.

62. Cranes Software (1991).

63. Janin R, Dandrekar P, Patravale VB (2007) Improving drug delivery-The nanoway.

64. Sundararajan G, Rao TN (2009) Commercial Prospects for Nanomaterials in India. J Indian Inst Sci 89.

65. Qtech Nanosystems (2004) Qtech nanosystems - Nano and beyond.

66. Cygnus research (2007) Indian nanotechnology industry.

67. Nanoscience and Technology Consortium (2005) Nanoscience and Technology Consortium.

68. Naseem M (2010) Energy law in India. Netherlands, Kluwer Law International 270.

69. Orinakova R, Orinak A (2011) Recent applications of carbon nanotubes in hydrogen production and storage. Fuel 90: 3123-40.

70. Chen G, Seo J, Yang C, Prasad NP (2013) Nanochemistry and nanomaterials of photovoltaics. Chem. Soc. Rev. 42: 8304-38.

71. Bettencourt LMA, Trancik JE, Kaur J (2013) Determinants of the pace of global innovation in energy technologies. PLoS One 8: e67864.

72. Amarasinghe UA, Shah T, Anand BK, Hugh, T (2007) India's water future to 2025-2050: Business-as-usual scenario and deviations. Eldis.

73. Qu X, Alvarez PJJ, Li Q (2013) Applications of nanotechnology in water and wastewater treatment. Water Research47: 3931-46. 
74. Mostafavi ST, Mehrnia MR, Rashidi MA (2009) Preparation of nanofilter from carbon nanotubes for application in virus removal from water. Desalination 238: 271-80.

75. International advanced research centre for powder Metallurgy and new materials (ARCI) (1997) International advanced research centre for powder Metallurgy and new materials (ARCI), Hyderabad - RTI.

76. Brandon C, Hommann K (1995) The cost of Inaction: Valuing the economy-wide costs of environmental degradation in India. In: Modeling Global Sustainability. Tokyo.

77. Leung R, Li J (2006) “Cultural Bonds” in high technology: Collaborations between chinese researchers in nanotechnology. Nanotech 2006 1: $584-7$.

78. Sharma V, Shukla RK, Saxena N (2009) DNA damaging potential of zinc oxide nanoparticles in human epidermal cells. Toxicology Letters 185: 211-8

79. Singh S, D’Britto V, Prabhune AA, Ramana CV, Dhawan A, et al. (2010) Cytotoxic and genotoxic assessment of glycolipid-reduced and -capped gold and silver nanoparticles. New J Chem 34: 294

80. The Royal Society \& The Royal Academy of Engineering (2004) Nanoscience and nanotechnologies: Opportunities and uncertainties. Cardiff, Clyvedon Press. Social and ethical issues: 51-6.

81. Feller I, Stern PC (2007) A strategy for assessing science. Washington DC, National Academies Press (US).

82. Macer DRJ (1995) Modern biotechnology: Legal, economic and social dimensions, Biotechnology ed. D. Brauer , Weinheim, Germany: VCH, 12 : 115.

83. Sparrow R (2009) The social impacts of nanotechnology: An ethical and political analysis. J Bioethical Inquiry 6: 13-23.

84. Puri IK (2008) Globalization

85. Diallo A, Street A, Sustich R, Duncan J, Savage N (2009) Nanotechnology applications for clean water: Solutions for improving water. Newyork, William Andrew Inc: 540 .

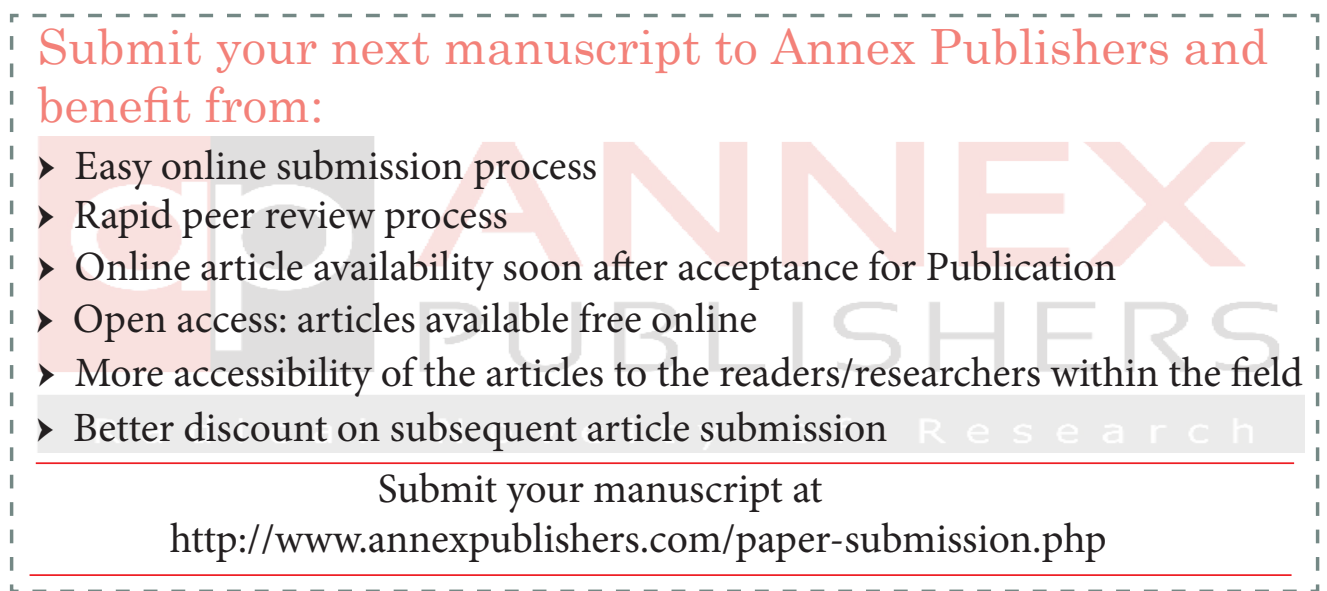

